\title{
PENGARUH MODEL PEMBELAJARAN STAD TERHADAP KEMAMPUAN PEMAHAMAN KONSEP SISWA DI MTS MIFTAHUL ULUM PANGKALAN BALAI
}

\author{
Wika Wiryanti ${ }^{1}$, Malalina ${ }^{2}$ \\ ${ }^{1}$ MTs Miftahul Ulum Pangkalan Balai Banyuasin III \\ ${ }^{2}$ Pendidikan Matematika FKIP Universitas Tamansiswa Palembang \\ wikawiryanti04@gmail.com
}

\begin{abstract}
The formulation of the problem in this study is whether there is an influence of the STAD learning model on the ability of students to understand mathematical concepts in MTs Miftahul Ulum Pangkalan Balai. The purpose of this study was to determine the significant effect of the STAD learning model on the ability of students to understand mathematical concepts in MTs Miftahul Ulum Pangkalan Balai. The learning model used is the pure experimental method (true experimental design) with the Posttest Only Control Design. The population in this study were all students of class VIII, while the sample in this study was class VIII.B of 30 students as the control class and VIII.E of 31 students as the experimental class. Data analysis techniques used are descriptive statistical techniques and Independent Sample Test. The results showed that there was a significant effect of the STAD learning model on students' mathematical concept understanding abilities at Miftahul Ulum Pangkalan Balai MTs. This was evident from the t-test.
\end{abstract}

Key Words: STAD, Concept Understanding

\begin{abstract}
Abstrak: Rumusan masalah dalam penelitian ini adalah apakah ada pengaruh model pembelajaran STAD terhadap kemampuan pemahaman konsep matematis siswa di MTs Miftahul Ulum Pangkalan Balai. Tujuan penelitian ini adalah untuk mengetahui pengaruh yang signifikan model pembelajaran STAD terhadap kemampuan pemahaman konsep matematis siswa di MTs Miftahul Ulum Pangkalan Balai. Model pembelajaran yang digunakan metode eksperimen murni (true eksperimental design) dengan desain Posttest Only Control Design. Populasi dalam penelitian ini adalah seluruh siswa kelas VIII, sedangkan sampel dalam penelitian ini adalah kelas VIII.B yang berjumlah 30 siswa sebagai sebagai kelas kontrol dan VIII.E yang berjumlah 31 siswa sebagai sebagai kelas eksperimen. Teknik analisis data yang digunakan adalah teknik statistik deskriptif dan Independent Sample Test. Hasil penelitian menunjukkan bahwa ada pengaruh yang signifikan model pembelajaran STAD terhadap kemampuan pemahaman konsep matematis siswa di MTs Miftahul Ulum Pangkalan Balai hal ini terlihat dari uji-t.
\end{abstract}

Kata Kunci: STAD, Pemahaman Konsep

\section{PENDAHULUAN}

Belajar juga sebagai rangkaian kegiatan jiwa raga, psiko-fisik untuk menuju ke perkembangan pribadi manusia seutuhnya yang berarti menyangkut unsur cipta, rasa dan karsa, ranah kognitif, afektif, dan psikomotorik (Sardiman, 2007). 
Kegiatan pembelajaran dilakukan oleh dua orang pelaku, yaitu guru dan siswa. Perilaku guru adalah mengajar dan perilaku siswa adalah belajar. Perilaku mengajar dan perilaku belajar tersebut terkait dengan bahan pembelajaran. Bahan pembelajaran dapat berupa pengetahuan nilai-nilai kesusilaan, seni, agama, sikap dan keterampilan. Pembelajaran merupakan suatu sistem, yang terdiri dari berbagai komponen yang saling berhubungan satu dengan yang lain (Rusman, 2010).

Untuk mencapai tujuan pembelajaran yang sejalan dengan perubahan paradigma dalam belajar, maka belajar tidak akan efektif jika anak duduk dengan manis di kelas sementara guru hanya memberikan materi kepada anak dengan berbagai hal. Guru sebagai sumber belajar sehingga hanya terfokus pada guru. Pembelajaran yang tidak mengajak siswa untuk lebih aktif dan guru yang lebih terhadap matematika (Aminah et al., 2016). Salah satu alternative untuk meningkatkan pemahaman konsep pembelajaran dalam matematika yakni dengan menerapkan model pembelajaran tipe STAD (Student Team Achievement Division) (Isjoni, 2011). Model pembelajaran tipe STAD (Student team Achievement Division) merupakan salah satu model pembelajaran kooperatif yang paling sederhana dan model yang paling baik bagi guru yang baru menggunakan pendekatan kooperatif (Slavin, 2005).

Untuk mendapatkan solusi dari permasalahan dalam pelaksanaan pembelajaran di SMP beberapa peneliti telah menerapkan model pembelajaran kooperatif tipe STAD diantaranya (Oktaviani et al., 2013), (Aminah et al., 2016) (Hartuti et al., 2016) yang menemukan dampak positif dari model STAD. Ketiga peneliti tersebut menekankan pada daya tarik matematik siswa aspek kognitif serta dilakukan penelitian pada tingkat SMP. Rumusan masalah dalam penelitian ini adalah adakah Pengaruh yang signifikan Model Pembelajaran STAD terhadap Pemahaman Konsep Matematis Siswa Kelas VIII MTs Miftahul Ulum Pangkalan Balai. Tujuan penelitian ini untuk mengetahui ada atau tidaknya pengaruh yang signifikan Model Pembelajaran STAD di SMP kelas VIII MTs Miftahul Ulum Pangkalan Balai.

\section{TINJAUAN TEORETIS}

\section{Kemampuan Pemahaman Konsep}

Pemahaman adalah kemampuan melihat hubungan- hubungan antara berbagai faktor atau unsur dalam situasi yang problematis. Sejalan dengan (Sagala, 2011), pemahaman (comprehension) adalah suatu kemampuan untuk mengerti dan memahami sesuatu setelah sesuatu itu diketaui atau diingat dan memaknai arti dari bahan maupun materi yang dipelajari. Menurut (Mudjiono, 2010) pemahaman yaitu mencakup kemampuan menangkap arti dan makna tentang hal yang dipelajari. Berdasarkan uraian diatas dapat disimpulkan bahwa kemampuan pemahaman konsep merupakan suatu kemampuan/kesanggupan untuk menafsir, memperkirakan, mengerti dan memahami konsep serta kemampuan menangkap arti dan makna 
suatu konsep yang dipelajari dan dapat mengelompokkan dan menjelaskan benda-benda (objek).

Adapun indikator

yang

menunjukkan pemahaman konsep

menurut Kurikulum 2006

(Kesumawati, 2010) terdapat 7 indikator. Indikator yang digunakan dalam penelitian ini hanya 4 indikator yaitu: Menyatakan ulang sebuah konsep; Memberikan contoh dan non contoh dari konsep; Menyajikan konsep dalam berbagai bentuk representatif matematis; menggunakan, memanfaatkan dan memilih prosedur atau operasi tertentu

\section{Pembelajaran Kooperatif Tipe STAD}

Pembelajaran kooperatif adalah strategi pembelajaran yang melibatkan partisipasi siswa dalam satu kelompok kecil untuk saling berinteraksi (Rusman, 2010). Model pembelajaran kooperatif memiliki beberapa tipe, salah satunya adalah STAD (student Team Achievement Division).STAD merupakan salah satu metode pembelajaran kooperatif yang paling sederhana, dan merupakan model yang paling baik untuk permulaan bagi para guru yang baru menggunakan pendekatan kooperatif (Slavin, 2005). Model STAD (Student Team Achievement Division) merupakan variasi pembelajaran kooperatif yang paling banyak diteliti. Model ini juga mudah diadaptasi, telah digunakan di matematika, IPA, IPS, Bahasa Inggris, Teknik dan banyak subjek lainya dan pada tingkat sekolah dasar sampai perguruan tinggi (Rusman, 2010).

\section{Langkah - langkah Pembelajaran} Kooperatif Model STAD

Adapun langkah-langkah pembelajaran STAD Menurut (Slavin, 2005) adalah:

- Penyampaian Tujuan dan Motivasi

- Pembagian Kelompok

- Presentasi dan Guru

- Kegiatan Belajar dalam Tim (Kerja Tim)

- Kuis (Evaluasi)

- Penghargaan Prestasi Tim

\section{Hubungan Antara STAD dengan Pemahaman Konsep Siswa}

Dalam

mempelajari matematika, pemahaman konsep matematika sangat penting untuk siswa. Karena konsep matematika yang satu dengan yang lain berkaitan sehingga untuk mempelajarinya harus tuntut dan berkesinambungan. Jika siswa telah memahami konsep-konsep matematika maka alan memudahkan siswa dalam mempelajari konsepkonsep matematika berikutnya yang lebih kompleks. Akan tetapi, hampir sebagian besar siswa justru mengaku bahwa mereka seringkali masih mengalami kesulitan untuk memahami pokok bahasan matematika yang dijelaskan oleh guru.Terlebih lagi jika mereka diberikan soal dengan sedikit variasi yang membutuhkan penalaran lebih. Hanya beberapa siswa yang mampu menjawab denga benar, itupun siswa-siswi yang memang tergolong pandai dari siswa lain di kelasnya. Dari beberapa kejadian tersebut menunjukkan bahwa pemahaman konsep matematika siswa masih rendah. 
Maka dari itu diperlukan suatu upaya guna meningkatkan pemahaman konsep matematika siswa. Salah satu upaya yang dilakukan yakni dengam menerapka model pembelajaran kooperatif tipe STAD (Student Team Achievement Division) dalam proses pembelajaran matematika di kelas. Model pembelajaran kooperatif tipe STAD merupakan salah satu tipe pelajaran kooperatif yang terdiri dari lima tahap pembelajaran yaitu prestasi kelas, belajar kelompok, kuis, peningkatan individu dan penghargaan kelompok. Setiap kelompok terdiri dari 4-5 anggota yang dituntut mandiri dan tidak tergantung pada anggota lain dan setiap siswa mendapat kesempatan yang sama agar kelompoknya mendapat nilai yang maksimal. Oleh karena itu setiap individu mempunyai tanggung jawab dalam megoptimalkan pencapaian tujuan pembelajaran matematika agar tercapai hasil belajar yang memuaskan.

\section{METODOLOGI PENELITIAN}

Subjek yang digunakan adalah nilai tes kemampuan konsep matematis siswa dari dua kelas yaitu Kelas Eksperimen dan Kelas Kontrol. Metode yang digunakan dalam penelitian ini adalah metode eksperimen sebenarnya ( true experimental design). Teknik yang digunakan dalam penelitian ini adalah metode tes. Dalam penelitian ini tes yang digunakan adalah terakhir (posttest) dalam bentuk soal essay berjumlah 5 soal. Uji coba insrumen meliputi validitas, reliabilitas, tingkat kesukaran dan daya pembeda. Teknik analisis data dalam penelitian ini menggunakan uji hipotesis (uji t), sebelum menggunakan uji $\mathrm{t}$ dilakukan uji prasyarat yaitu uji normalitas dan uji homogenitas.

\section{HASIL DAN PEMBAHASAN}

Peneliti mengambil dua kelas, yaitu kelas VIII.B sebagai kelas kontrol dengan jumlah 31 siswa dan kelas VIII.E sebagai kelas eksperimen dengan jumlah siswa 30 siswa.

Penelitian terbagi menjadi empat kali pertemuan, pada pertemuan pertama membahas materi tentang jarring-jaring dan luas permukaan prisma, pertemuan kedua membahas materi volume prisma, pertemuan ketiga membahas masalah sehari-hari yang bersangkutan dengan luas permukaan dan volume prisma, dan pertemuan keempat merupakan tes akhir (posttest) terhadap kemampuan pemahaman konsep matematis dengan materi bangun ruang sisi datar prisma. Soal tes berupa soal tertulis yang berbentuk uraian sebanyak 4 soal yang mencakup seluruh materi yang telah diajarkan mulai dari pertemuan pertama sampai pertemuan ketiga.

Tabel 1

Rata-rata Kemampuan Pemahaman Konsep Matematis Siswa

\begin{tabular}{|c|c|c|c|c|}
\hline \multirow{2}{*}{ Kelas } & \multicolumn{3}{|c|}{ Pertemuan } & \multirow{2}{*}{ Rata } \\
\cline { 2 - 5 } & $\mathbf{1}$ & $\mathbf{2}$ & $\mathbf{3}$ & $\begin{array}{c}\text { Rata } \\
\text { Eksperimen }\end{array}$ \\
& 54,50 & 61,33 & 72,16 & 62,66 \\
\hline Kontrol & 49,13 & 59,82 & 65,17 & 58,04 \\
\hline
\end{tabular}

Tabel 1 didapat kesimpulan bahwa nilai rata-rata kemampuan pemahaman konsep matematis siswa pada pembelajaran matematika menggunakan model pembelajaran STAD dikelas eksperimen lebih tinggi 
dibandingkan dengan

kemampuan pemahaman konsep matematis siswa pada pembelajaran matematika menggunakan model pembelajaran konvensional.

Dari tes yang diberikan kepada sampel penelitian, jawaban dianalisis untuk menghitung kemampuan pemahaman konsep matematis siswa.

Tabel 2

Perbandingan Data Posttest Kemampuan Pemahaman Konsep Matematis

\begin{tabular}{c|c|c}
\hline \multirow{2}{*}{ Statistik } & \multicolumn{2}{|c}{$\begin{array}{c}\text { Kemampuan Pemahaman } \\
\text { Konsep Matematis }\end{array}$} \\
\cline { 2 - 3 } & Eksperimen & Kontrol \\
\hline$N$ & 20 & 20 \\
\hline $\bar{X}$ & 79,28 & 61,95 \\
\hline Maks & 92,85 & 75 \\
\hline Min & 60,71 & 42,85 \\
\hline Mo & 71,42 & 64,28 \\
\hline \multicolumn{2}{|c}{ Tabel 2 diperoleh rata-rata }
\end{tabular}

kemampuan pemahaman konsep matematis siswa setelah diterapkan model pembelajaran STAD pada materi bangun ruang prisma 79,28 dan ratarata pada kelas yang menggunakan metode konvensional 61,95. Dari ratarata tersebut dapat kita lihat bahwa rata-rata per-indikator kemampuan pemahaman konsep matematis siswa dikelas eksperimen lebih besar dari pada kelas kontrol. Dengan daya pembeda rata-rata kemampuan pemahaman konsep matematis siswa kelas eksperimen dan kelas kontrol maka perlu dilakukan analisis statistik dengan pengujian statistik uji-t untuk mengetahui ada atau tidaknya pengaruh model pembelajaran kooperatif tipe STAD terhadap kemampuan pemahaman konsep matematis siswa di MTs Miftahul Ulum Pangkalan Balai, maka terlebih dahulu dilakukan uji normalitas dan uji homogenitas.

Tabel 3

Uji Normalitas Data Kemampuan Pemahaman Konsep Matematis Tests of Normality

\begin{tabular}{l|r|r|r}
\hline \multirow{2}{*}{} & \multicolumn{3}{|c}{ Kolmogorov-Smirnov $^{\mathrm{a}}$} \\
\cline { 2 - 4 } & Statistic & \multicolumn{1}{c}{ Df } & \multicolumn{1}{c}{ Sig. } \\
\hline Kelas & .157 & 20 & $.200^{*}$ \\
Eksperimen & & & \\
Kelas & .199 & 20 & .037 \\
Kontrol & & &. \\
\hline
\end{tabular}

a. Lilliefors Significance

Correction

*. This is a lower bound of the true significance.

Berdasarkan tabel diatas di dapat nilai Kolmogorov - Smirnov dengan taraf signifikan sebesar 0,200 kelas eksperimen dan 0,037 untuk kelas kontrol. Berdasarkan kriteria $H_{0}$ diterima. Sehingga dapat disimpulkan bahwa data di atas berdistribusi normal.

Tabel 4

Hasil Tes Homogenitas Data

Test of Homogeneity of Variances

Nilai_Kelas_Ekperimen

\begin{tabular}{|c|c|c|c|}
\hline $\begin{array}{c}\text { Levene } \\
\text { Statistic }\end{array}$ & df1 & df2 & Sig. \\
\hline 3.098 & 5 & 12 & .050 \\
\hline
\end{tabular}

Berdasarkan tabel di atas di dapat nilai Lavene Statistic sebesar 3,098 dan Sig $=0,050$. Berdasarkan kriteria $H_{0}$ diterima. Sehingga dapat disimpulkan bahwa variansi dari dua kelas tersebut adalah homogen. Artinya tidak ada perbedaan variansi yang signifikan antara kelas kelas ekserimen dan kelas kontrol. 


\begin{tabular}{|c|c|}
\hline \multicolumn{2}{|c|}{$\begin{array}{c}\text { Tabel } 5 \\
\text { Hasil Uji }-\mathbf{t}^{\text {Test Statistics }}{ }^{\mathrm{D}}\end{array}$} \\
\hline & Nilai Posttest \\
\hline Mann-Whitney U & 35.000 \\
\hline Wilcoxon W & 245.000 \\
\hline Z & -4.501 \\
\hline Asymp. Sig. (2-tailed) & .000 \\
\hline $\begin{array}{l}\text { Exact Sig. [2*(1-tailed } \\
\text { Sig.)] }\end{array}$ & $.000^{a}$ \\
\hline
\end{tabular}

a. Not corrected for ties.

b. Grouping Variable: kelas

Berdasarkan hasil perhitungan pada tabel 4.6 diperoleh nilai sig. (2tailed) $=0,000$ dan ini menunjukkan bahwa $H_{0}$ diterima yang berarti "Ada pengaruh yang signifikan model pembelajaran kooperatif tipe STAD terhadap kemampuan pemahaman konsep matematis siswa di MTs Miftahul Ulum Pangkalan Balai". Dengan kata lain bahwa model pembelajaran kooperatif tipe STAD lebih baik dari pada pembelajaran konvensional.

\section{SIMPULAN DAN SARAN}

Berdasarkan hasil analisis data dan pembahasan, maka dapat disimpulkan bahwa ada pengaruh Model Pembelajaran STAD terhadap Kemampuan Pemahaman Konsep Matematis Siswa di MTs Miftahul Ulum Pangkalan Balai. Hal ini ditunjukkan oleh Hasil penelitian menunjukkan bahwa ada pengaruh yang signifikan model pembelajaran STAD terhadap kemampuan pemahaman konsep matematis siswa di MTs Miftahul Ulum Pangkalan Balai hal ini terlihat dari uji-t diperoleh sig. $(1$-talied $)=0,000<0,05$, maka $H_{0}$ ditolak dan $H_{a}$ diterima. Nilai rata-rata tes akhir (posttest) kemampuan pemahaman konsep matematis siswa pada kelas eksperimen yaitu 79,28 lebih tinggi dibandingkan dengan kelas kontrol yaitu 61,95.

\section{UCAPAN TERIMA KASIH}

Ucapan terima kasih penulis sampaikan kepada Kepala dan Guru MTs Miftahul Ulum Pangkalan Balai.

\section{DAFTAR PUSTAKA}

Aminah, S., Afri, L. E., \& Arcat. (2016). Pengaruh Model Pembelajaran Kooperatif Tipe STAD terhadap Kemampuan Pemahaman KonsepMatematis siswa SMPN 1 Rambah Hilir. Jurnal Mahasiswa FKIP Universitas Pasir Pangaraian, 2(2).

Hartuti, Samparadja, H., \& Awaludin. (2016). Penerapan Model Pembelajaran Kooperatif Tipe STAD Setting Reciprocal Teaching untuk Meningkatkan Hasil Belajar Matematika SMP N10 Poleang Selatan Bombama. Jurnal Penelitian Pendidikan Matematika. Jurnal Penelitian Pendidikan Matematika, 4(1).

Isjoni. (2011). Cooperative Learning Efektivitas Pembelajaran Kelompok. Alfabeta.

Kesumawati, N. (2010). Peningkatan Kemampuan Pemahaman Pemecahan Masalah dan Disposisi Matematis Siswa SMP Melalui Pendekatan Pendidiakan Matematika Realistis. Universitas Pendidikan Indonesia.

Mudjiono. (2010). Konsep dan Makna Pembelajaran. Rineka Cipta.

Oktaviani, P., Nurhanurawati, N., \& Coesamin, M. (2013). Pengaruh Penerapan Model Pembelajaran Kooperatif tipe STAD Terhadap Pemahaman Konsep matemati Siswa. Jurnal Pendidikan 
Matematika Universitas Lampung, 1(5).

Rusman. (2010). Model-model pembelajaran. Raja Grafindo Persada.

Sagala, S. (2011). Konsep dan Makna Pembelajaran. Alfabeta.

Sardiman. (2007). Interaksi dan Motivasi BelajarMengajar. Raja Grasindo Persada.

Slavin, R. E. (2005). Cooperatif Learning Teori, Riset dan Praktik. Nusamedia. 